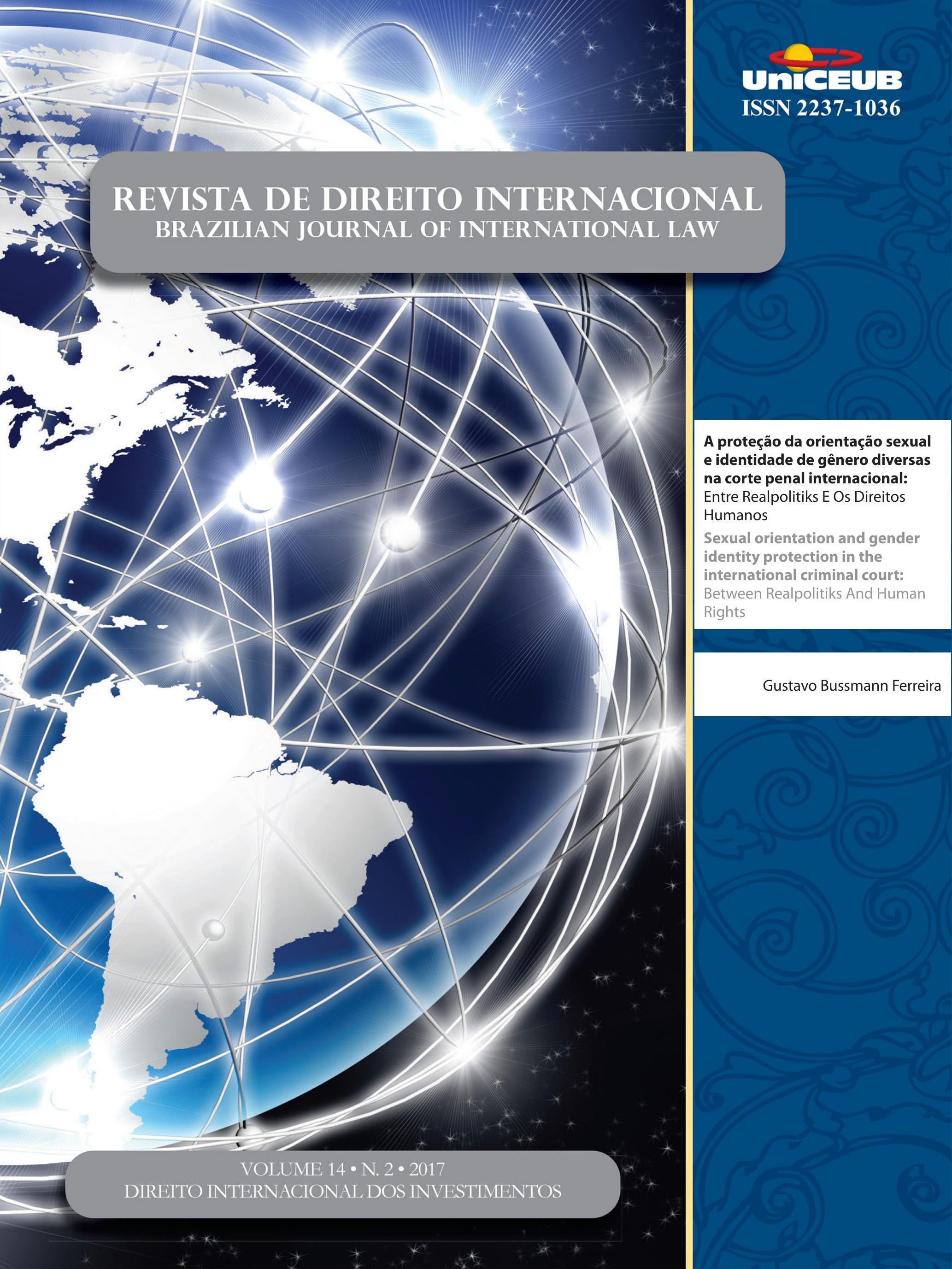




\section{Sumário}

I. Crônicas do Direito Internacional ...............................................1

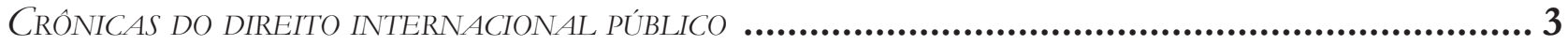

A resolução 2272 (2016) do Conselho de Segurança das Nações Unidas - O POSICIONAMENTO DA ONU FACE ÀS ALEGAÇÕES DE ABUSO E EXPLORAÇÃo SEXUAL POR SUAS

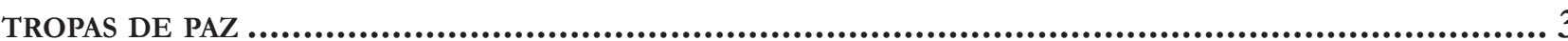

Sarah Dayanna Lacerda Martins Lima

CRÓNICAS DE DiREITo INTERNACIONAL PRIVADO...................................................................

Nadia de Araujo, Marcelo De Nardi, Gustavo Ribeiro, Fabrício Polido e Inez Lopes

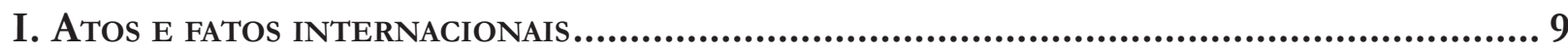

Crônica 1. Novidades de 2017 SObRE CIRCulaÇÃo faCilitada DE SENTENÇAS ESTRANGEIRAS 9

Crônica 2: O Direito Transnacional e os episódios das Carnes.........................................16

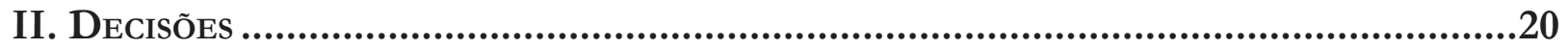

Crônica 3: A Irresistível ForÇa da ORDEM PÚblica E A HOMOLOGaÇÃo DE SENTENÇAS

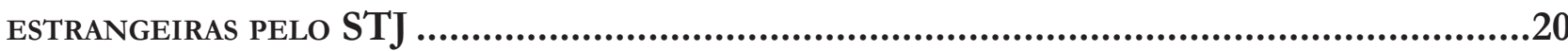

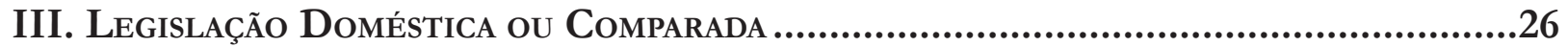

Crônica 4 - Dignidade da pessoa humana e mudança de paradigma da Lei de Migração

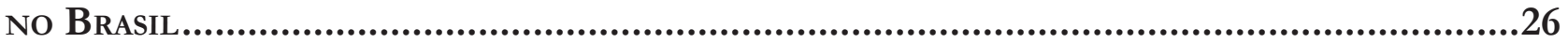

II. Dossiê especial: Direito Internacional dos InVEstimentos ................35

Non-adjudicatory State-State Mechanisms in Investment Dispute Prevention and Dispute Settlement: Joint Interpretations, Filters and Focal Points 
Mapping the Duties of Private Companies in International Investment Law .50 Nitish Monebhurrun

LA LÉGALITÉ DE L'INVESTISSEMENT DEVANT L'ARBITRE INTERNATIONAL: À LA RECHERCHE D'UN POINT D'ÉQUILIBRE .73 Hervé Ascensio

Host STATES AND STATE-STATE INVESTMENT ARBITRATION: STRATEGIES AND CHALlENGES......81 Murilo Otávio Lubamdo de Melo

Right to Regulate, Margin of Appreciation and Proportionality: Current Status in Investment Arbitration in Light of Philip Morris V. Uruguay. .95 Giovanni Zarra

Investments on Disputed Territory: Indispensable Parties and Indispensable Issues....122 Peter Tzeng

The Influence of General Exceptions on the Interpretation of National

Treatment in INTERNATIONAL INVESTMENT LAW. 140 Louis-Marie Chauvel

UMA PRoposta de REFleXão SObRe os ACFIs: Até QUE PONTO O TRATAMENTo de NAÇão MAIS FAVORECIDA PODE MINAR A ESTRATÉGIA POLÍTICA QUE OS EMBASA? 160

Michelle Ratton Sanchez Badin, Daniel Tavela Luis e Mario Alfredo de Oliveira

ECUADOR's 2017 TERMINATION OF TREATIES: HOW NOT TO EXIT THE INTERNATIONAL INVESTMENT REGIME 179

Jose Gustavo Prieto Muñoz

ONE BELT, ONE ROAD: NOVAS INTERFACES ENTRE O COMÉRCIO E OS INVESTIMENTOS INTERNACIONAIS 193

Flávio Marcelo Rodrigues Bruno e Marilda Rosado de Sá Ribeiro

III. Artigos Sobre outros TEMAS..................................................... 214

TolerânCIA E REFugIO: UM ENSAIO A PARTIR Do ACORdo EU-TurQUiA 216 Flávia Cristina Piovesan e Ana Carolina Lopes Olsen 
O TRATAMENTO do APÁtridA NA NOVA LEI DE MIGRAÇÃo: ENTRE AVANÇOS E RETROCESSOS...237 Jahyr-Philippe Bichara

O caráter humanista da Lei de Migrações: aVAnços da Lei N. 13.445/2017 E Os desafios DA REGULAMENTAÇÃO. 254 Marcelo Dias Varella, Clarice G. Oliveira, Mariana S.C. Oliveira e Adriana P. Ligiero

Reform of the United Nations Security Council: The Emperor Has No Clothes.268 Ljubo Runjic

A IDEIA DE QUe os LATINO-AMERICANOS PREFEREM O AUTORITARISMO À DEMOCRACIA À luz da reinterpretação dos Critérios do Programa das Nações Unidas para o DesenVolvimento 286

Gina Marcilio Pompeu e Ana Araújo Ximenes Teixeira

A PRoteção da ORIENTAÇÃo SEXUAL E IDENTIDAdE DE GÊNERO DIVERSAS NA CORTE PENAL internacional: Entre Realpolitiks E Os Direitos Humanos

Gustavo Bussmann Ferreira

A desnacionalização e as violações de direitos humanos na República Dominicana. 331 Daniela Menengoti Gonçalves Ribeiro e Rodrigo Ichikawa Claro Silva

CompetênCia do TPI no Caso do ATAque ao hospital de Kunduz: uma análise ENVOLVENDO A JURISDiÇÃo do TPI EM RELAÇÃO A NACIONAIS DE EsTAdOS NÃO-PARTE do Estatuto DE Roma

Filipe Augusto Silva e Renata Mantovani de Lima

A CRIMINALIZAÇÃo DOS IMIGRANTES EM SITUAÇÃo IRREGULAR NA ITÁliA: BIOPOLÍtica E DIREITO PENAL DO AUTOR.

Maiquel Angelo Dezordi Wermuth e Jeannine Tonetto de Aguiar

The New Rules On Trade And Environment Linkage In Preferential Trade Agreements

Alberto do Amaral Júnior e Alebe Linhares Mesquita

Beyond THE Border between the North and the South: towards a Decolonization of EPISTEMOLOGIES AND FIELDS OF RESEARCH ON MERCOSUR 
A aplicabilidade da Convenção de Montreal no direito brasileiro.

Aziz Tuffi Saliba e Alexandre Rodrigues de Souza

REgIME DE TRANSPARÊNCIA FISCAL NA TRIBUTAÇÃo DOS LUCROS AUFERIDOS NO EXTERIOR (CFC RULES): LACUNAS E CONFLITOS NO DIREITO BRASILEIRO

Paulo Rosenblatt e Rodrigo Torres Pimenta Cabral

As Regras Brasileiras de Tributação de Controladas e Coligadas no Exterior: verdadeiras Controlled Foreign Company (CFC) Rules? .......................................465

Melina de Souza Rocha Lukic e Amanda Almeida Muniz

O RETORNO DE BENS CULTURAIS

Aziz Saliba e Alice Lopes Fabris

Direitos culturais e Nações Unidas: uma análise a partir da Declaração Sobre a eliminação de Todas as Formas de Intolerância e Discriminação Baseadas na Religião OU NA CRENÇA

Leilane Serratine Grubba e Márcio Ricardo Staffen

OS REFLEXOS DA PROTEÇÃO INTERNACIONAL DA PROPRIEDADE INTELECTUAL PARA O DESENVOLVIMENTO INTERNO: UMA ANÁLISE SOBRE O SISTEMA PATENTÁRIO BRASILEIRO E A TRANSFERÊNCIA DE TECNOLOGIA

Michele M. Segala e Isabel Christine S. De Gregori

O CASO HIPOTÉTICO DA MORTE DO EMBAIXADOR FRANCÊS NA ESPANHA: DUAS ESPÉCIES DE IUS gentium em Francisco de Vitoria

Rafael Zelesco Barretto

De volta À BeVilaqua: anÁlise ECONÔMICA dA APLICAÇão do ART. $9^{\circ}$ DA LINDB Às OBRIGAÇÕES CIVIS CONTRATUAIS

Danielle Cristina Lanius e Ivo Teixeira Gico Jr 


\title{
A proteção da orientação sexual e identidade de gênero diversas na corte penal internacional: Entre Realpolitiks E Os Direitos Humanos*
}

\author{
Sexual orientation and gender identity \\ protection in the international criminal \\ court: Between Realpolitiks And Human Rights
}

Gustavo Bussmann Ferreira**

\section{Resumo}

Tendo em vista o necessário cuidado que se deve dispensar às populações vulnerabilizadas, tratados, bem como os estigmas heteronormativos presentes no Estatuto de Roma, nos permite situar o problema e orientar este estudo para um segundo enfoque; verificar bem como a importante atuação do direito internacional para reverter situações de invisibilidade que acometem determinados nichos populacionais, o presente trabalho se propõe a analisar os limites e possibilidades da Corte Penal Internacional na proteção dos direitos da população LGBTTI. Para tanto, compreender o papel da realpolitiks na elaboração, assinatura e ratificação dos o Documento Programático do Gabinete do Procurador e o comprometimento da CPI em proteger pontualmente e especificamente essa população, no mesmo sentido, orientará as respostas do questionamento proposto para uma análise dos Crimes Contra a Humanidade e Genocídio desse grupo social que se reconhece nas pessoas não heterossexuais. Assim, na medida em que, ainda, não há consenso nem jurisprudência sobre o assunto e a proteção da população dos indivíduos em sua sexualidade, é premente e necessária no atual momento social em que nos encontramos, tratar de questões de política e direito internacional, reconhecimento da população LGBTTI e proteção de suas vulnerabilidades é imperioso para que se possa apontar novos rumos para que a CPI ultrapasse as barreiras formais de suas normas.

* Recebido em 21/12/2016

Aprovado em 07/06/2017

** Doutorando em Direitos Humanos e Democracia pelo Programa de Pós-Graduação da Universidade Federal do Paraná. Mestre em Direitos Humanos e Democracia pela mesma instituição (2015). Membro do grupo de pesquisa Direitos Humanos e Vulnerabilidades da Universidade Federal do Paraná. Membro do grupo de pesquisa e iniciação científica em Direito Internacional Penal do Unicuritiba entre 2010 e 2015. Trial Monitor pela American Bar Association - casos selecionados - desde Fevereiro de 2015. Advogado. E-mail: gus.bussmann@ gmail.com

\section{Abstract}

Taking into consideration the adversities that exist in the elaboration, signature and ratification of international treaties, mostly when with regards to human rights and aspirations to harmonise diverse cultures and interests; universal and particular perspectives of rights, we can considerate that practices may face strong difficulties when referring to issues on gender and sexuality. In this way, the present work aims to analyse Realpolitiks in international human rights law, the Policy Paper on Sexual and Gender-Based 
Crimes of the Office of the Prosecutor of the International Criminal Court; also, to analyse how the Rome Statute may protect people of diverse sexual orientation and gender identities. From the norms referring to genocide and crimes against humanity, as persecution, the comprehension that there is a social group consistent of non heterosexual people seems essential to strengthen the protection of these citizens and to accomplish the intentions of international justice of value human rights and singularities of life.

Keywords: Realpolitiks. International Criminal Court. Sexual Orientation. Persecution.

\section{INTRODUÇão}

Diversos acontecimentos do último século deixaram um legado de insegurança e temor nas sociedades ocidentais em virtude das graves reiteradas violações a direitos humanos ocorridas. O regime nacional socialista alemão e suas vítimas, a guerra da Iugoslávia e o novo pânico de que o terror se espalhasse pelo mundo ocidental e o genocídio ruandês da década de 90 são, apenas, alguns exemplos de conflitos internacionais que marcaram o Direito contemporâneo. Essas marcas advêm das diversas (re)significações que se deram aos direitos individuais, às novas compreensões de um direito internacional para proteção dos cidadãos e, também, dos Tribunais ad hoc que criaram jurisprudência e estabeleceram uma nova forma de encarar o Direito e as identidades.

Tribunais de Nuremberg e do Extremo Oriente, tal como os Tribunais Penais Internacionais para a Ex-Iugoslávia e Ruanda, são a prova de que há um compromisso mundial com a intolerância à impunidade e com a robusta e consistente proteção que se intenta aos direitos humanos.

Sem tamanha projeção internacional, mas também relevante para o estudo que se propõe, podem-se destacar alguns pleitos sociais que, também, se mostram importantes para, contemporaneamente, possibilitar novas compreensões a direitos e identidades. Os movimentos raciais, por exemplo, que lutaram por políticas de igualdade e equidade; os movimentos feministas que, contundentemente, defenderam uma nova colocação social, econômica e política às mulheres; bem como os movimentos de proteção a direitos orientação sexual e identidade de gênero diversa ${ }^{1}$, que de inúmeras formas fortaleceram as percepções particulares e sociais desse grupo.

O pleito de cidadãos homossexuais carrega estigmas e dificuldades de fortalecimento em disputas entre o pretenso universalismo dos direitos humanos em contraponto a um particularismo que respeita tradições culturais e religiosas.

Nos Estados Unidos da América, por exemplo, pouco ganhou notoriedade internacional o fundamento dos pleitos por reconhecimento e inclusão social mesmo tendo sua luta tomado grandes proporções no âmbito doméstico. Muitas das vitórias conseguidas em juízo em relação à população homossexual advêm de analogias propostas com o movimento por direitos raciais $^{2}$, no seguinte sentido: as intenções de negar características homossexuais ou reconhecimento da população enquanto grupo foram sendo deixadas de lado para, em estratégias mais exitosas, apontar discriminações no ambiente de trabalho e ofensas à primeira emenda da constituição norte americana, dentre outros. Para isso, o caminho escolhido foi, então, o comparativo e alegações referentes aos precedentes de discriminação racial ${ }^{3}$. Relembra-se: a primeira emenda trata basicamente das proibições à limitação da liberdade de expressão e ao direito de livre associação pacífica ${ }^{4}$. Todavia, conforme se perceberá ao longo deste trabalho, é importante que se retomem questões relativas ao que determina a existência de um grupo social e como, objetiva ou subjetivamen-

1 Opção aqui se faz pela terminologia Orientação Sexual e Identidade de Gênero (SOGI) diversas, de modo a tentar englobar direitos de homossexuais (gays e lésbicas), bissexuais, transexuais, transgêneros, intersexuais, dentre outros. A proposta, portanto, para fugir de siglas muito extensas e deveras categorizantes, como LGBTTI, se faz no sentido de compreensão aberta e fluída, de modo a abarcar todos aqueles que não se encaixam nas possibilidades binárias que a sociedade oferece. Da mesma forma, o termo SOGI foi também a opção do Alto Comissariado das Nações Unidas em proposta semelhante, conforme se pode perceber nas documentações, orientações e informações oficiais. Conforme: Sexual Orientation and Gender Identity. Disponível em: < http://www.refworld. org/sogi.html>.

2 Nesse sentido verificar: KONNOTH, Craig J. Created in Its Image: the Race Analogy, Gay Identity, and Gay Litigation in the 1950s-1970s. The Yale Law Journal, v. 119, n. 2, Nov. 2009.

3 ESKRIDGE JUNIOR, William N. Some Effects of Identity-Based Social Movements on Constitutional Law in the Twentieth Century. Yale: FacultyScholarship Series, 2002. p. 2161-2169.

4 CONSTITUIÇÃO dos Estados Unidos da América. Legal Information Institute. Cornwell University Law School. Disponível em: <https://www.law.cornell.edu/constitution/first_amendment>. Acesso em: 28 ago. 2016. 
te, se percebem os indivíduos como parte desse grupo.

Também, os movimentos feministas, profunda e substancialmente, se relacionam com a pauta dos direitos de pessoas de SOGI diversa, na medida em que refutam uma compreensão binária da sociedade (homem e mulher, macho e fêmea, e assim por diante) no sentido de dar maiores garantias de direitos e igualdade social sem que isso signifique limitação de formas de viver. Da mesma forma, países do oriente médio têm os movimentos de proteção dos direitos das mulheres agidos de forma contundente na proteção dos direitos de pessoas não heterossexuais, visto que, normalmente, estas são colocadas em situação de extremos perigo e de vulnerabilidade.

Pelo exposto, recente e relevante a luta por reconhecimento e por direitos da população de SOGI diversa, bem como com substanciais similitudes com pleitos de muitos outros nichos populacionais, entende-se por importante a análise dos direitos dessas pessoas no atual momento político e social que se vive. Ainda, na medida em que o atual sistema internacional de proteção dos direitos humanos não se posicionou claramente sobre as possibilidades de resguardar e efetivar esta gama de direitos, a proposta que se faz é de apontar em que medida está a Corte Penal Internacional ${ }^{5}$ apta a agir e consolidar novos entendimentos sobre o tema. A compreensão dos limites e possibilidades dessa corte para julgar crimes praticados contra a população não heterossexual, inclusive, permite novas perspectivas para sua atuação - o que se propõe a partir da interpretação de Crimes Contra a Humanidade e de Genocídio.

Dessa feita, o presente trabalho se dividirá em três etapas para compreender quais são as potencialidades guardadas pela Corte Penal Internacional em relação à proteção dos direitos de pessoas de SOGI diversa: em relação à declaração de 2014 do Gabinete do Procurador - considerando-se as intenções do legislador e questões de realpolitiks; do crime de genocídio a partir da compreensão de pessoas não heterossexuais como membros de um grupo identificável; e dos crimes contra a humanidade em se tratando de perseguição.

5 O recorte que aqui se faz se deve ao formato deste trabalho, que não comportaria análise suficiente e adequado a todo o sistema internacional de proteção dos direitos humanos. Ainda, a opção pela Corte Penal Internacional se faz na medida em que se enxergam diversas potencialidades de proteção, como adiante se poderá perceber.
Acredita-se que, ao explorar essas possibilidades guardadas pela lei formal (Estatuto de Roma) e pelos documentos anexos que devem influenciar a interpretação da norma pelos legisladores, pode-se lançar luz sobre como o direito internacional poderá ser importante para a proteção desses direitos, ainda tão violados. Sob vulnerabilidades e invisibilidades, a confiança que se deposita no direito internacional dos direitos humanos, portanto, é a de que possa ser instrumento de novas significações e novas formas de proteção àqueles que pleiteiam o direito de viver as suas singularidades.

\section{Realpolitiks e a Criação do Estatuto de ROMA}

Com a assinatura do Estatuto de Roma em 17 de julho de 1998, seguida do início da atuação da Corte Penal Internacional em Haia ${ }^{6}$, na Holanda (doravante determinada CPI), o panorama mundial de proteção dos direitos fundamentais ganhou novos contornos. Também o pleito dos cidadãos pela proteção de suas identidades ${ }^{7}$ ganhou novo corpo nos últimos vinte anos, de modo que posicionamentos positivos em relação a essa proteção se esperam dos atores políticos e dos institutos de proteção de direitos. Especificamente em relação à CPI, possui, também, um papel emblemático ao reproduzir uma mensagem de que a impunidade não mais será tolerada, reforçando a importância de se dispensar especial atenção aos direitos de identidade e reconhecimento - atrelados ao mais profundo significado dos direitos humanos.

Há que se considerar, nesse sentido, que a assinatura

6 A nomenclatura de Corte, não Tribunal Penal Internacional é adotada desta forma devido ao seu caráter permanente e de não se tratar de uma jurisdição ex post facto, tal como seriam as instituições denominadas tribunais. UNITED Nations Research Guide. Disponível em: <research.un.org/en/docs/law/courts>. Acesso em: 23 jun. 2014. Sobre o assunto, consultar, também: FERREIRA, Gustavo Bussmann. A Identificação das Vitimas para o Direito Internacional dos Direitos Humanos: entre a universalidade dos direitos e a vida nua. Disponível em: < http://acervodigital.ufpr.br/bitstream/ handle/1884/37933/R\%20-\%20D\%20-\%20GUSTAVO $\% 20$ BUSSMANN $\% 20$ FERREIRA.pdf?sequence $=3>$. Acesso em: 17 nov. 2016.

7 Aqui, desde logo se sublinha a ausência de intenção em reduzir a termo o que compreende uma percepção identitária e em que medida considera-se aquilo que remonta a identidade de um indivíduo. O termo é utilizado no sentido das aspirações dos cidadãos na defesa de direitos intimamente ligados com suas particularidades, singularidades e formas de vida. 
de um tratado como o Estatuto de Roma (ER) envolve a acomodação de interesses e premissas de diversas nações. Assim, necessariamente, alguns direitos serão deixados de lado a fim de garantir que a intenção de criação de uma jurisdição internacional seja atingida. Por esse motivo, antes de se analisarem as especificidades da Corte Penal Internacional acerca dos crimes praticados contra a população de SOGI diversa, o conceito de realpolitiks deve ser perpassado na medida em que considera não apenas aspectos formais da política, mas suas adaptações e desvios para a preservação de interesses daqueles que a operam. Para além de considerações éticas ou compromissos com os direitos humanos e os cidadãos $^{8}$, há que se considerar a conjuntura que levou à realização de certos atos ou assinatura de determinados tratados (em detrimento do que seria esperado para que se atingissem os objetivos iniciais de uma corte ou da proteção dos direito humanos).

Ainda, é importante que, antes de se analisarem os limites e possibilidades de que a Corte Penal Internacional receba denúncias e julgue os crimes cometidos contra a população de SOGI diversa, que se analise o conteúdo do Estatuto de Roma em sua proposta original e a forma final que adquiriu a partir de discussões e interesses políticos dos países que o assinaram. Ainda, vale ressaltar que se possuísse forma e conteúdo diversos dos que se apresentam hoje em sua versão oficial, talvez o instrumento não fosse assinado e ratificado.

Posteriormente, apresentam-se considerações acerca da resolução do Gabinete do Procurador da CPI (Office of the Prosecutor) de Junho de 2014, Policy Paper on Sexual and Gender-Based Crimes, doravante denominado Documento Programático para Crimes Sexuais e de Gênero. Uma vez que tal documento não faz parte do Estatuto de Roma em sua via original e não se trata de algo similar a uma emenda, na medida em que não foi objeto de discussões e votação tal como o ER antes de sua assinatura, sua legitimidade poderá ser questionada quando vier a ser mencionado nas decisões dos juízes da CPI.

Assim, as considerações do presente capítulo seguirão a mencionada ordem, incursões em realpolitiks, o conteúdo do Estatuto de Roma em sua versão original e, no capítulo seguinte, sobre o conteúdo do Documento Programático de 2014 do Procurador da CPI na tentativa de esclarecerem-se alguns pontos e levantarem-se

8 ENCICLOPAEDIA Brittanica. Disponível em: <https://global. britannica. com/topic/realpolitik>. Acesso em: 10 nov. 2016. questionamentos sobre os limites e possibilidades de o documento assinado pelo procurador da Corte Penal Internacional seja efetivo na alteração do Estatuto de Roma e seja aplicado pelos julgadores da Corte.

Conforme já mencionado, tratar de realpolitik envolve questionar como as decisões foram tomadas e quais os interesses dos atores políticos preponderaram em determinadas situações. O termo foi cunhado, originalmente, em contraste à idealpolitiks, políticas ideais que acomodassem diplomacia internacional e aspirações democráticas 9 . Dessa forma, a análise de um tratado ou de determinada ação política deve envolver as manobras de coalizão existentes nos bastidores, os jogos de poder, as forças sociais e as possibilidades políticas que dão forma e conteúdo ao direito internacional dos direitos humanos.

Há que se reconhecer, portanto, que existem mecanismos reguladores que atuam sobre a população global na intenção de que seja gerida a partir de saberes específicos. Assim, por meio da segurança, da economia política, soberania e controle, dentre inúmeras outras variáveis, o direito internacional dos direitos humanos se constrói e se forja. Nesse sentido:

O fato de que os homens essencialmente aplicam seu poder sobre outros homens dá ao conceito, na política, seu significado autêntico. O poder de um indivíduo é a capacidade de fazer, mas, antes de tudo, é a capacidade de influir sobre a conduta ou aos sentimentos dos outros indivíduos. No campo das relações internacionais, poder é a capacidade que tem uma unidade política de impor suas vontades às demais. Em poucas palavras, o poder político não é um valor absoluto, mas uma relação entre os homens ${ }^{10}$.

Nesse esteio, não se pode esquecer de que as conquistas relacionadas aos direitos humanos no último século foram, também, produto de relações de poder e de intenções particulares; de relações entre os homens permeadas por anseios, disputas e pelo Direito. O exemplo norte-americano mencionado, acerca da conquista de direitos homossexuais a partir de analogias com pleitos de movimentos raciais, retrata as dificuldades de pleitearem-se direitos e como as estratégias de litigância se

9 KELLY, Duncan. Realpolitik: a history, by John Bew. Financial Times, 2016. Disponível em: <https://www.ft.com/ content/802c822e-d0d6-11e5-831d-09f7778e7377>. Acesso em: 17 nov. 2016.

10 ARON, Raymond. Paz. e Guerra entre as Nações. Brasília: Universidade de Brasília, Instituto de Pesquisa de Relações Internacionais; São Paulo: Imprensa Oficial do Estado de São Paulo, 2002. p. 99. 
mostraram essenciais para que os pedidos fossem contemplados.

Justamente por isso, tem-se que os direitos humanos são conquistados, adquiridos, produto de luta e diálogos - o que fica ainda mais acentuado em um período de globalização e de intenções de um sistema normativo de larga escala. Considerar-se que há uma intenção global de governança, portanto, uma mundialização esperada em relação ao direito a ter direitos, implica transcender soberanias e repensar a autodeterminação dos po$\operatorname{vos}^{11}$. Todavia, Essa construção dos direitos humanos coaduna-se com a busca pela efetivação de um mundo comum regulado por um Direito que igualmente proteja a todos.

Ainda, pensar a conquista de direitos envolve, também, ultrapassar as barreiras do formalismo legal. Tome-se como exemplo o caso da jurisprudência brasileira: o Poder Judiciário nacional, em primeiro e segundo graus ignora, diariamente, as normativas internacionais e os tratados assinados e ratificados pelo país ao promover julgamentos e tomada de decisões. A Suprema Corte (Supremo Tribunal Federal), por sua vez, também não possui histórico robusto ou coerente na utilização do aparato internacional de direitos humanos. Quando teve a oportunidade, inclusive, ao julgar a possibilidade de união civil entre pessoas do mesmo sexo (denominada homoafetiva pela literatura e jurisprudência), eximiu-se o relator de fundamentar sua decisão em princípios do direito internacional dos direitos humanos ou em diálogos inter-cortes; pelo contrário, o que se fez foi fundamentar a decisão em trechos literários e em uma construção lógica que deixou a desejar do ponto de vista jurídico e político.

Vale dizer que a utilização do termo homoafetividade, por exemplo, utilizada para evitar os preconceitos carregados pelo sinônimo homosexualidade, pode iludir que a simples alteração semântica seria suficiente para maior reconhecimento e inclusão; ora, algo que só se atinge com robusto trabalho de conscientização, ressignificação das relações e efetiva hospitalidade - para além da letra fria da lei e da jurisprudência. Ainda, é importante reconhecer que o voto do relator possui grande fundamentação em aspectos biológicos e se esquece de criar um fio condutor nas citações de doutrina, nacional

11 LAFER, Celso. Reconstrução dos direitos humanos: um diálogo com o pensamento de Hannah Arendt. Rio de Janeiro: Companhia das Letras, 2001. p. 127. e estrangeira, que se usa para justificar suas decisões ${ }^{12}$.

Por outro lado, Não obstante a existência de diversas leis e tratados que se referem à proibição de discriminação em virtude de orientação sexual e identidade de gênero, a realidade, ainda, se mostra pouco favorável para a vida digna e segura dessa população. Se, por um lado, os standards internacionais reconhecem avanços na realidade nacional em virtude de inexistência de criminalização das condutas e da possibilidade de casamento entre pessoas do mesmo sexo, a realidade se mostra muito menos receptiva e celebratória dessa população. Claro exemplo que se aborda é a inexistência de criminalizado dos crimes de ódio praticados contra a população de orientação sexual e identidade de gênero diversas; assim, a cada 28 horas o país permite uma morte provocada por homo-lesbo-trans-fobia e se resguarda de investigar e julgar os motivos que possibilitam esta realidade ${ }^{13}$.

Dessa forma, pensar em um Direito que se proponha global e igualmente protetor de todos os cidadãos onde quer que vivam, requer que sejam questionados a forma pela qual esse Direito passa a ser válido, como as normas são criadas e de que forma se pretendem neu$\operatorname{tras}^{14} \mathrm{o}$ suficiente para que não sejam aplicadas de forma desigual; ainda, em que medida a aplicabilidade e a legitimidade desse Direito devem ser permanentemente objeto de atenção - seu enforcement em níveis nacionais e internacionais, sua validade, apesar da soberania e as (im)possibilidades de ser descartado em situações pontuais com justificativas na autodeterminação dos povos.

Vale ressaltar que o direito internacional em muito se baseia em valores globais e nas intenções de efetivação do previsto na Declaração Universal dos Direitos Humanos. A consciência que se propõe é a de união de todos os povos a partir do seu reconhecimento de uns

12 Ver mais informações em: BRITTO, Carlos Ayres. O bumanismo como categoria constitucional. Belo Horizonte: Fórum, 2016; BRASIL. Supremo Tribunal Federal. Voto do Ministro Carlos Ayres Britto no julgamento conjunto da ADPF 132 e ADI 4277. Disponível em: $<$ http://www.stf.jus.br/arquivo/cms/noticiaNoticiaStf/anexo/ ADI4277revisado.pdf $>$.

13 Para mais informações sobre os dados mencionados nesta seção, consultar: PESQUISAS realizadas pelo Grupo Gay da Bahia: associação de defesa dos direitos da população de SOGI diversa no país desde 1980. Disponível em: <http://www.ggb.org.br/>. Acesso em: 8 fev. 2017.

14 Consultar: BASSIOUNI, M. Cherif. Searching for Justice in the World of Realpolitik: 12 Pace Int'l L, 2000. Disponível em: <http:// digitalcommons.pace.edu/pilr/vol12/iss2/1>. Acesso em: 18 nov. 2016. 
nos outros por laços comuns, de que todas as culturas têm por base uma herança partilhada. Assim, falar-se em pureza de normas se refere a valores, moralmente, neutros que podem ser utilizados para a proteção de quaisquer pessoas e países, igualmente aplicáveis por vítimas e acusados.

Nesse panorama, debruçar-se sobre a forma que os tratados são feitos e assinados rememora-nos que o direito internacional é tão forte quanto os estados que o criam e balizam pretendem que o sej $\mathrm{a}^{15}$. A assinatura de um tratado ou a submissão a um sistema internacional de direitos pode advir do fato de que, simplesmente, por apoiar determinadas questões é politicamente válido e interessante; da mesma forma, não há uma "polícia internacional" ou um método de coerção e imposição de obrigatoriedade para que se cumpra com o disposto nos tratados. Nesse sentido:

\begin{abstract}
Todas as Nações são tentadas a vestir suas próprias aspirações e ações particulares com a roupagem dos fins morais do universo - e poucas foram capazes de resistir à tentação por muito tempo. Uma coisa é saber que as Nações estão sujeitas à lei moral, e outra, muito diferente, é pretender saber, com certeza, o que é bom ou mau no âmbito das relações entre Nações ${ }^{16}$.
\end{abstract}

Referido trecho nos permite encarar com maior crítica e seriedade, por exemplo, o fato de o Conselho de Segurança das Nações Unidas possuir os Estados Unidos, Rússia, China como membros permanentes. Ao mesmo tempo, referido Conselho tem poder de denunciar ao Procurador qualquer situação em que haja indícios de ter ocorrido a prática de um ou vários desses crimes previstos no Estatuto de Roma. Ainda, os membros permanentes possuem poder de veto em relação às decisões tomadas pelo Conselho. Ou seja: apesar de não se submeterem à jurisdição da Corte Penal Internacional, os três mencionados países possuem papel determinante na decisão de quais países terão seus líderes levados a julgamento.

A jornada empreendida até a criação da Corte Penal Internacional, portanto, segue na tentativa de que seus propósitos iniciais sejam alcançados, pelo fim da impunidade e pela efetivação dos direitos humanos. Mas entre soluções políticas e valores morais, não se pode

15 BASSIOUNI, M. Cherif. Searching for Justice in the World of Realpolitik: 12 Pace Int'l L, 2000. Disponível em: < http://digitalcommons.pace.edu/pilr/vol12/iss2/1>. Acesso em: 18 nov. 2016.

16 MORGENTHAU, H. A política entre as Nações. Brasília: Funag/ IPRI, EdUNB; São Paulo: Imprensa Oficial do Estado, 2003. p. 21. deixar de questionar cada um dos atos de interpretação dos seus instrumentos, tratados e princípios. Para além de interesses públicos e privados, de representantes de nações e de interesses políticos, de moralismos utópicos e interesses concretos ${ }^{17}$, não se deve aceitar o direito e as cortes internacionais como livre de vícios e falhas. $\mathrm{O}$ que se propõe, em contrapartida, é um olhar atento e cuidadoso para que os freios e contrapesos constantes não deixem que o sistema internacional de proteção dos direitos humanos venha a se tornar um mero meio para se atingir resultados políticos ${ }^{18}$.

Quando dos trabalhos preparatórios para a elaboração do Estatuto de Roma, inúmeras discussões perpassaram os procedimentos para que se chegasse a um consenso sobre o texto final - o suficiente para agradar a todos os 60 estados parte que o ratificaram em 1998. No preâmbulo de referido dispositivo, fez-se constar algumas premissas para a criação de uma Corte Penal Internacional. Nesse sentido:

Conscientes de que todos os povos estão unidos por laços comuns e de que suas culturas foram construídas sobre uma herança que partilham, e preocupados com o fato deste delicado mosaico poder vir a quebrar-se a qualquer instante, Tendo presente que, no decurso deste século, milhões de crianças, homens e mulheres têm sido vítimas de atrocidades inimagináveis que chocam profundamente a consciência da humanidade $[\ldots]^{19}$. (grifo nosso).

Reforçando a intenção de refletir certo grau de universalidade dos direitos humanos, por algum motivo, optou-se por deixar claro a intenção de proteger homens e mulheres. Considerando-se a intenção de proteger a humanidade como um todo, pode-se questionar o porquê de tal escolha em detrimento da proteção mais genérica 'de todos os seres humanos', por exemplo.

Em seu artigo $07^{\circ}$, ao elencar as previsões de crimes contra a humanidade, o parágrafo $03^{\circ}$ assim dispõe: "Para efeitos do presente Estatuto, entende-se que o termo "gênero" abrange os sexos masculino e feminino,

17 KELLY, Duncan. Realpolitik: a history, by John Bew. Financial Times, 2016. Disponível em: <https://www.ft.com/ content/802c822e-d0d6-11e5-831d-09f7778e7377>. Acesso em: 17 nov. 2016.

18 BASSIOUNI, M. Cherif. Searching for Justice in the World of Realpolitik: 12 Pace Int'l L, 2000. Disponível em: <http://digitalcommons.pace.edu/pilr/vol12/iss2/1>. Acesso em: 18 nov. 2016.

19 BRASIL. Decreto n. 4.388, de 25 de setembro de 2002. Estatuto de Roma do Tribunal Penal Internacional. Disponível em: <http://www. planalto.gov.br/ccivil_03/decreto/2002/D4388.htm>. 
dentro do contexto da sociedade, não lhe devendo ser atribuído qualquer outro significado ${ }^{20}$. Ainda, o apego a essa forma restrita de interpretação das questões de identidade de gênero são reiteradas no artigo 21 do mesmo estatuto, quando assim prevê:

\begin{abstract}
A aplicação e interpretação do direito, nos termos do presente artigo, deverá ser compatível com os direitos humanos internacionalmente reconhecidos, sem discriminação alguma baseada em motivos tais como o gênero, definido no parágrafo 30 do artigo 7o, a idade, a raça, a cor, a religião ou o credo, a opinião política ou outra, a origem nacional, étnica ou social, a situação econômica, o nascimento ou outra condição.
\end{abstract}

De fato, se aparenta paradoxal um instrumento internacional de proteção que faz referências explícitas aos direitos humanos e a proibição de discriminação e ao mesmo tempo, por mais de uma vez, sublinha a impossibilidade de considerar gênero para além de conceitos estanques de masculino e feminino. Sobre essas delimitações binárias em relação à sexualidade humana, vale o questionamento sobre a possível redução das multiplicidades da vida a, apenas, duas possibilidades: sexo masculino e feminino. Em contrapartida, alocar interesses dos países da Europa, Oriente Médio, Extremo Oriente, Latino-Americanos..., com todas as suas particularidades, não se mostra tarefa fácil. Assim, trabalhar com o consolidado no instrumento legal é o que resta como possibilidade para os aplicadores e como esperança para as vítimas diárias de violações em razão de sua orientação sexual e identidade de gênero. Hannah Arendt assim tratou da dificuldade em se dar efetividade aos direitos humanos a partir da letra fria da lei:

Os Direitos do Homem, supostamente inalienáveis,
mostraram-se inexequíveis - mesmo nos países
cujas constituições se baseavam neles - sempre
que surgiam pessoas que não eram cidadãos
de algum Estado soberano. A esse fato, por si já
suficientemente desconcertante, deve acrescentar-
se a confusão criada pelas numerosas tentativas de
moldar o conceito de direitos humanos no sentido
de defini-los com alguma convicção, em contraste
com os direitos do cidadão, claramente delineados ${ }^{21}$.

O paradoxo percebido é que a mesma pluralidade que fundamentou a criação dos direitos humanos foi os levou à sua insuficiência para os cidadãos. Ao se-

20 BRASIL. Decreto n. 4.388, de 25 de setembro de 2002. Estatuto de Roma do Tribunal Penal Internacional. Disponível em: <http://www. planalto.gov.br/ccivil_03/decreto/2002/D4388.htm>.

21 ARENDT, Hannah. As Origens do Totalitarismo. São Paulo: Companhia das Letras, 1990. p. 326. rem tratados, tecnicamente, como iguais em todos os lugares do mundo, os cidadãos perdem em reconhecimento de suas culturas e em suas necessidades individuais; demonstram que a mera declaração de valores é insuficiente para a manutenção da dignidade que lhes é necessária. Ou seja, os cidadãos querem participar, mas querem, também, ser reconhecidos em sua individualidade, o que requer o afastamento da despersonalização dos povos e suas culturas ${ }^{22}$. Assim, questionar-se não apenas a insuficiência da terminologia empregada pelo Estatuto de Roma, mas também suas origens e suas potencialidades se afigura importante para a proteção efetiva dos direitos humanos e para a efetividade da Corte Penal Internacional.

Há que se analisar, também, para além das insuficiências contidas no texto legal e da problemática em se reduzir as proteções de gênero a "masculino e feminino", as discussões que perpassaram a elaboração do texto final. Por exemplo, é sabido que, em 11 de Julho 1998, nos trabalhos preparatórios para a elaboração do texto legal do Estatuto de Roma, Austrália, Bélgica, Canadá, Chile, Costa Rica, Finlândia, Grécia, França e mais doze países se posicionaram oficialmente para que o termo 'gênero' fosse mantido nos dispositivos legais. Já outros como Egito, Guatemala, Líbia, Qatar, Venezuela, dentre outros, solicitaram formalmente a retirada do termo ${ }^{23}$. Alguns problemas levantados eram concernentes às dificuldades de assinatura de um tratado que envolva a redefinição dos moldes culturais existentes em uma sociedade, bem como a impossibilidade de tradução do termo "gênero" para as seis línguas oficiais da Organização das Nações Unidas; nos documentos em árabe e francês, por exemplo, as referências são feitas aos "dois sexos" 24 .

Ainda, há que se considerar a possibilidade de novos direitos serem garantidos às mulheres a partir de interpretações mais abrangentes do termo gênero e para além do que as legislações nacionais já possibilitassem.

22 DELMAS-MARTY, Mireille; CASSESSE, Antonio. Crimes Internacionais e Jurisdições Internacionais. Barueri: Manole, 2004. p. 61-72. 23 OOSTERVELD, Valerie. Diplomatic Conference of Plenipotentiaries on the Establishment of the International Criminal Court: Notes From Working Group on Applicable Law. 1998. p. 63. Disponível em: $<$ http://www.legal-tools.org/uploads/tx_ltpdb/Oosterveld _Gender_HarvardArticle2005_02.pdf>. Acesso em: 20 nov. 2016.

24 OOSTERVELD, Valerie. The Defintion of "Gender" in the Rome Statute of the International Criminal Court. a Step Forward or Back for International Criminal Justice? Disponível em: <http://www.legaltools.org/uploads/tx_ltpdb/Oosterveld_Gender_HarvardArticle2005_02.pdf>. Acesso em: 20 nov. 2016. 
Percebe-se, portanto, um claro exemplo de realpolitiks e do temor que um conflito entre legislações enfraquecesse a política nacional. Há maior valorização, portanto, da soberania e do modelo cultural vigente do que à proteção de determinada parcela da população. No mesmo sentido, considerar gênero para além dos clássicos significados, masculino e feminino, significaria "reestruturar drasticamente as sociedades ao redor do mundo vastas [...] o que raramente se enquadraria na agenda de uma Corte Penal (Internacional) ${ }^{25}$ ".

Por fim, antes de encaminhar nossas ponderações para o sopro de ar fresco que traz o Documento Programático do Gabinete do Procurador da CPI e em complementação ao que se expôs na referência bibliográfica de número 1 em que se explica nossa opção metodológica pelo termo SOGI, cabe apresentar algumas considerações sobre gênero e sexualidade. Primeiramente, posiciona-se no sentido de que a sigla LGBTTQI (lésbicas, gays, bissexuais, transexuais, transgêneros, queer e intersexuais) pode não representar todas as possibilidades a partir do que as pessoas lidam com suas próprias identidades, singularidades e sexualidades.

Ademais, deve-se considerar situações como a da Comissão de Direitos Humanos da cidade de Nova York que lançou uma lista exaustiva de 31 possíveis identidades sexuais e de gênero a serem reconhecidas. Assim, em vez das 07 letras representativas da população LGBTTQI, passamos a refletir sobre as 31 possibilidades trazidas pelo governo de NY, bem como sobre as muitas outras possibilidades pelas quais o ser humano poderia se identificar. Destarte, nenhuma lista de letras seria longa o suficiente para determinar as possíveis identificações fluídas do ser humano. Há que se ressaltar, no mesmo sentido, que a letra 'Q', em menção ao que seriam pessoas queer, não deve ser interpretada como uma forma de identidade, mas um conceito guarda-chuva que acoberta todas as possibilidades de viver as sexualidades para além dos tradicionais papéis dominantes hetero-cis ${ }^{26}$.

Conforme documentado e partilhado pelo Centro

25 KENNEDY, David M. Center for International Studie: What's the Argument for "Gender Justice?". Disponível em: < http://www. legal-tools.org/uploads/tx_ltpdb/Oosterveld _Gender_HarvardArticle2005_02.pdf>. Acesso em: 20 nov. 2016.

26 To further information, please refer to: NEW York City Hall, Gender Identity/Gender Expression: Legal Enforcement Guidance. Disponível em: <https://www1.nyc.gov/site/cchr/law/legal-guidances-gender-identity-expression.page\#2>. Acesso em: 20 nov. 2016. de Pesquisa em equidade de Gênero da Universidade de Berkeley, concorda-se com a afirmação de que se identificar como queer é, também, um ato político no sentido de romper com concepções binárias e reconhecer orientação sexual e identidade de gênero como potencialmente fluídos - como um simples conceito que se propõe a acolher uma complexa gama de comportamentos e desejos sexuais. Na medida em que as intenções de proteção dos cidadãos em relação a suas sexualidades e singularidades perpassa o comprometimento em evitar rótulos e respeitar a potencialidade humana tanto quanto possível, reitera-se que o uso do termo SOGI é adequado uma vez que compreende todas as possibilidades existentes em relação à sexualidade humana.

Pelo exposto, confirmada a necessária compreensão da sexualidade em perspectivas flutuante e fluída, a negação de rótulos e do sistema binário de compreensões se reforça, assim como a insuficiência do texto legal do Estatuto de Roma. Assim, orienta-se a próxima seção para a análise do Documento Programático do Procurador da Corte Penal Internacional como possibilidade de novas formas de interpretação e, consequentemente, nova esperança para a população queer em situação de vulnerabilidade.

\section{O Documento Programático do Gabinete do Procurador para Crimes Sexuais e De Gênero e Possíveis Interpretações do Estatuto de Roma}

Para tentar driblar as dificuldades de promulgar alguma emenda ao Estatuto de Roma ou de meramente aguardar uma reinterpretação do texto legal pelos juízes da corte, em 2014 o Gabinete do Procurador publicou um Documento Programático para Crimes Sexuais e de Gênero. Não se trata, portanto, de uma alteração de competência ou de uma afronta à comunidade internacional em tentativa de desconstruir as previsões acordadas e positivadas no ER. Trata-se da explicitação de um comprometimento do Gabinete do Procurador em alçar questões de gênero e sexualidade a um de seus objetivos estratégicos de proteção internacional dos cidadãos, integrando à sua atuação perspectivas críticas, 
maximizando a importância do efeito deterrance ${ }^{27}$ e do desafio às sociedades hierárquicas, reivindicando, assim, as potencialidades da vida dos cidadãos.

A grande importância do texto concentra-se na possibilidade que se abre de interpretar todo e qualquer crime previsto no Estatuto de Roma como se de possível cometimento a partir de uma perspectiva de gênero. Diz o parágrafo 20 do Documento Programático:

Within the scope of its mandate, and in a manner consistent with article 54(1)(a) of the Statute, the Office will apply a gender analysis to all of the crimes within its jurisdiction. This involves an examination of the underlying differences and inequalities between women and men, and girls and boys, and the power relationships and other dynamics which determine and shape gender roles in a society, and give rise to assumptions and stereotypes. In the context of the work of the Office, it requires a consideration of whether, and in what ways, crimes, including sexual and gender-based crimes, are related to gender norms and inequalities. The approach by the Office will also encompass an understanding of the use of certain types of crimes, including acts of sexual violence, to diminish gender, ethnic, racial, and other identities ${ }^{28}$.

A jurisprudência das Cortes Internacionais já vinha consolidando entendimento de que não apenas as violações previstas nos parágrafos de crimes sexuais estavam sujeitas ao exercício de sua jurisdição. A Corte Especial de Serra Leoa ${ }^{29}$, por exemplo, ao compreender que o

27 No sentido de dissuadir novos perpetradores que repitam crimes de mesma natureza, que novas violações venham a acontecer. KIM, Hunjoon; SIKKINK Kathryn. Explaining the Deterrence Effect of Human Rights Prosecutions for Transitional Countries. 2009. Disponível em: < http://iilj.org/courses/documents/Sikkink-Kim. HC2009Oct21.pdf >. Acesso em: 5 set. 2016.

28 Em tradução livre: No escopo deste documento, e de forma consistente com o artigo 54(1)(a) do Estatuto (de Roma), o Gabinete irá aplicar uma análise sob a perspectiva de gênero a todos os crimes sob sua jurisdição. Isso envolve o exame das diferenças sublinhadas e desigualdades entre mulheres e homens, e meninas e meninos; bem como do poder das relações afetivas e de outras dinâmicas que determinam e moldam os papeis de gênero em uma sociedade e permitem o estabelecimento de premissas e estereótipos. No contexto de seu trabalho, o Gabinete requer a consideração de como e de qual forma crimes, incluindo os sexuais e baseados em gênero, se relacionam com normas de gênero e desigualdades. A abordagem do Gabinete irá, também, englobar a compreensão do uso de certos tipos de crimes, incluindo atos de violência sexual, para diminuir identidades de gênero, étnicas, raciais e outras.

29 Trata-se de uma Corte Híbrida, que mescla lei nacional e costumes com o direito internacional; tipo de corte importante para o direito internacional dos direitos humanos uma vez que adaptada para uma situação em específico, levando em consideração as circunstâncias histórico-sociais e antropológicas do local onde ocor- crime de casamento forçado deve ser considerado como possível objeto de sua jurisdição, permite que nova amplitude seja dada ao teor do Estatuto de Roma na questão de "outros atos desumanos". O Estatuto prevê em seu artigo 07(1)(g) a criminalização de "Agressão sexual, escravatura sexual, prostituição forçada, gravidez forçada, esterilização forçada ou qualquer outra forma de violência no campo sexual de gravidade comparável"30. Todavia, apesar de o legislador não ter sido específico em relação à prática de casamentos forçados, mulheres do mundo todo foram contempladas com esperança desde que a conduta passou a ser percebida como um crime contra a humanidade à luz do artigo 07(1)(k) do Estatuto de Roma ${ }^{31}$, quando prevê "Outros atos desumanos de caráter semelhante, que causem intencionalmente grande sofrimento, ou afetem gravemente a integridade física ou a saúde física ou mental”32.

À parte dos crimes de conotação sexual, cuja proteção legal remonta ao estatuto do Tribunal Penal Internacional para a ex-Iugoslávia ${ }^{33}$ pelo caráter explorador

reram os crimes. Uma intervenção externa poderia levantar diversas questões de legitimidade aos cidadãos envolvidos em conflitos em regiões remotas e isoladas; no mesmo sentido, a sociedade civil poderia enfrentar inúmeros desafios ao julgar crimes dessa magnitude, pelo que a complementaridade partilhada (shared complementarity) se mostra uma maneira efetiva de junção de esforços entre Estados e organizações internacionais para a construção da paz. Os tribunais domésticos internacionalizados, portanto, são vistos como um caminho do meio para que se chegue à efetividade das cortes internacionais, pois possuem parâmetros internacionalmente reconhecidos como a presunção da inocência e o devido processo legal, bem como recursos financeiros que não estariam disponíveis em julgamentos em cortes domésticas. Consultar: BRINGING Justice: the Special Court for Sierra Leone. Reported at Human Rights Watch em tradução livre. Disponível em: <http://www.hrw.org/node/11983 /section/2>. Acesso em: 24 out. 2014; ORGANIZAÇÃO DAS NAÇÕES UNIDAS. Role of Civil Society in Post-Conflict Peace-Building: 4993 encontro do Conselho de Segurança, Nova Iorque, 22 jun. 2004. Disponível em: <http:/ /www.securitycouncilreport.org/ atf/ cf/\%7B65BFCF9B-6D27-4E9C-8CD3-CF6E4FF96FF9\%7D/ PKO\%20SPV \%204993.pdf>. Acesso em: 10 out. 2014; SCHARF, Michael P. Forward: lessons from the Saddam Trial. Local: Faculty Publications; Case Western Reserve University, 2007. p. 7.

30 BRASIL. Decreto n. 4.388, de 25 de setembro de 2002. Estatuto de Roma do Tribunal Penal Internacional. Disponível em: <http://www. planalto.gov.br/ccivil_03/decreto/2002/D4388.htm>.

31 CLARK, James M. Forced Marriage: the Evolution of a New International Criminal Norm. Aberdeen: University of Aberdeen, 2013. v. 3.

32 BRASIL. Decreto n. 4.388, de 25 de setembro de 2002. Estatuto de Roma do Tribunal Penal Internacional. Disponível em: <http://www. planalto.gov.br/ccivil_03/decreto/2002/D4388.htm>.

33 TRIBUNAL Penal Internacional para a Ex-Iugoslávia. Estatuto do Tribunal Penal Internacional para a Ex-Iugoslávia, de 25 de maio de 1993. 
de cumprir atividades domésticas e atividades sexuais ${ }^{34}$, a corte considerou crime a conduta dos casamentos forçados devido à análise da gravidade que enseja e o grande sofrimento que inflige às vítimas também na questão psicológica $^{35}$ : não se considera, apenas, a questão sexual do ato, mas o fato de ser desumano também em seus demais aspectos (não sexuais). Enquanto a jurisprudência para a Ex-Iugoslávia considera os crimes sexuais na medida do sentimento de propriedade que possui o perpetrador $^{36}$, o crime de casamento forçado possui, além desse aspecto, o terror psicológico que as vítimas sofrem uma vez que a violência inclui manipulações intelectuais, obrigações domésticas e sexo/engravidamento não consensual ${ }^{37}$.

Trata-se, portanto, de claro exemplo de interpretação sob uma perspectiva de gênero de uma norma que não foi necessariamente assim constituída. A Corte Interamericana de Direitos Humanos, no mesmo sentido, se pronunciou a respeito da problemática envolvendo "papeis sociais socialmente construídos" em sua jurisprudência relativa ao caso Karen Atala Riffo vs. Chile. Após o fim de sua relação com o esposo, a Juíza de Direito Karen Atala manteve a guarda das filhas. Todavia, ao comprometer-se em um relacionamento com outra mulher, tempos depois, Karen foi confrontada em juízo por seu ex-marido que pretendia reaver a guarda das filhas do casal unicamente em função de sua nova condição homossexual. Segundo alegado pelo pai e confirmado pela Suprema Corte Chilena, ao envolver-se em relacionamento afetivo com outra pessoa de seu mesmo sexo, a sra. Karen estaria pondo em risco a educação de suas filhas ao não cumprir com o papel social que deveria.

O caso foi submetido à Comissão Americana de Direitos Humanos (CIDH) e posteriormente encaminhado à Corte Interamericana de Direitos Humanos, a qual condenou o estado chileno pela clara discriminação institucional sofrida por Atala no curso do processo de guarda, violando os artigos 11 (proteção à honra e à

34 TRIBUNAL Penal Internacional para a Ex-Iugoslávia. Promotor vs. Kunarac (12 Prosecutor vs. Kunarac et al.). Caso n. IT-96$23 T$ \& IT-96-23/1-T, Julgamento de 22 fev. 2001. p. 742.

35 CORTE Especial para Serra Leoa. Promotor vs. Alex Tamba Brima. Caso n. SCSL-2004-16-A. Julgamento de 3 mar. 2008. p. 854.

36 TRIBUNAL Penal Internacional para a Ex-Iugoslávia. Promotor vs. Kunarac (12 Prosecutor vs. Kunarac et al.). Caso n. IT-96$23 T$ \& IT-96-23/1-T, Julgamento de 22 fev. 2001. p. 539.

37 CORTE Especial para Serra Leoa. Promotor vs. Alex Tamba Brima. Caso n. SCSL-2004-16-A. Julgamento de 3 mar. 2008. p. 61. dignidade), 17 (proteção à família), 19 (direitos da criança), 24 (igualdade perante a lei), 8 (garantias judiciais) e 25 (proteção judicial), todos combinados com o artigo 1 (obrigação de respeitar direitos), da Convenção Americana de Direitos Humanos $(\mathrm{CADH})$.

Comprometer-se com a análise de todo o Estatuto de Roma sob uma perspectiva de gênero possibilita, portanto, o rompimento com algumas normas cuja potencialidade de aplicação houvesse sido eivada quando da escrita do Estatuto. Assim, não obstante as questões de realpolitiks já explicitadas, as dificuldades no estabelecimento de um consenso em relação ao que será positivado nos tratados e na impossibilidade de um direito internacional ser construído de forma a alterar, substancialmente, o sistema jurídico doméstico dos seus países signatários, o Documento Programático do Gabinete do Procurador para Crimes Sexuais e de Gênero reafirma as intenções de promoção e defesa dos direitos de uma população diariamente violada em sua honra, dignidade e identidades.

Dessa maneira, todas as previsões do Estatuto de Roma tornam-se sujeitas a análise sob uma perspectiva crítica e consideração de eventuais particularidades referentes a identidades de gênero e diversidade sexual. Todavia, duas formas de percepção de crimes contra a população de SOGI diversa se apresentam mais palpáveis, de modo que serão exploradas com mais cuidado, quais sejam: o crime de genocídio e os crimes contra a humanidade. O primeiro, em interpretação extensiva do caput quando trata de intenções de extermínio e destruição de um grupo. Já em relação aos crimes contra a humanidade, em compreensão de que perseguição pode em relação a grupo ou coletividade que possa ser identificado por motivos políticos, raciais, nacionais, étnicos, culturais, religiosos ou de gênero.

\section{Crimes de Genocídio e Contra a HUMANIDADE}

Em relação ao crime de genocídio, considera-se que pode ocorrer em vertente física, biológica ou cultural ${ }^{38}$, mas a preocupação que causa (e por isso a sua denominação como crime dos crimes) não se refere, apenas, ao

38 SCHABAS, William A. An Introduction to the International Criminal Court. 4. ed. New York: Cambridge University Press, 2011. p. 102. 
sofrimento em larga escala impingido às vítimas diretas. Atenta-se, também, para a angústia que envolve os fundamentos da prática, que estão "acima da compreensão humana ${ }^{39}$ ", para a pretensa homogeneização das sociedades e a impossibilidade de partilhar o espaço social com aqueles que não compactuam com uma forma de vida determinada pelo poder hegemônico.

O crime de genocídio, ao identificar grupos por meio da estigmatização pelos ofensores ${ }^{40}$ e promover a citada exclusão de alguns da vida em sociedade, é o mote de governos totalitários e retira dos cidadãos o acesso ao espaço público e o direito de pertencer a uma comunidade $^{41}$. Esse sistema de organização da vida, portanto, retira de alguns seres humanos a cidadania, o direito a ter direitos, a igualdade e a liberdade essenciais a uma vida digna. Desta forma, considerando que o caput do art. $06^{\circ}$ do Estatuto de Roma menciona grupos nacionais, étnicos, raciais ou religiosos, considerando o Documento Programático do Gabinete do Procurador, tem-se que o aplicador não pode se furtar de analisar o contexto da prática de crimes sob um viés crítico que perceba as violações existentes em relação às comunidades e pessoas de SOGI diversa.

Partindo-se do pressuposto de que cabe ao Estado não apenas medidas positivas de proteção ao cidadão, mas que, também, não se abstenha de empreender esforços para que as cartas constitucionais e tratados internacionais sejam materialmente cumpridos, há que se destinar especial atenção a duas das possibilidades previstas no artigo $06^{\circ}$ do Estatuto de Roma. São elas: "b) Ofensas graves à integridade física ou mental de membros do grupo; c) Sujeição intencional do grupo a condições de vida com vista a provocar a sua destruição física, total ou parcial".

Ainda, vale dizer que o crime de genocídio pode ocorrer em duas fases: "a primeira consiste na destruição do modelo nacional do grupo oprimido e a segunda, na imposição de um modelo nacional de opressor

39 ARENDT, Hannah. Eichmann em Jerusalém: um relato sobre a banalidade do mal. Tradução: José Rubens Siqueira. 5. reimpr. São Paulo: Companhia das Letras, 1999. p. 232.

40 Tribunal Penal Internacional para a ex-Iugoslávia, Prosecutor vs. Krstic, julgamento de 2 de agosto de 2001, parágrafo 557: "scientifically objective criteria" were considered "inconsistent with the object and purpose of the convention".

41 LAFER, Celso. A Reconstrução dos Direitos Humanos: a contribuição de Hannah Arendt. Estud.av, São Paulo, v. 11, n. 30, mayo/ aug. 1997. Disponível em: <http://dx.doi.org/10.1590/S010340141997000200005>. Acesso em: 20 jun. 2014. sobre a população oprimida que ficou no território ${ }^{42}$ ". Vale ressaltar, novamente, a compreensão de que sexo e gênero são sujeitos a constituição social e que nisto podem se fundamentar os comportamentos de opressão e as justificativas genocidas contra aqueles que não se enquadram em uma "matriz de heterossexualidade compulsória". Dessa forma, as estruturas de significação do homossexual (e daqueles que não compreendem a parcela heterossexual desejada e hegemônica) resultam na criação de normas reguladoras que definem também as práticas e legitimidades desses indivíduos. Nas palavras de Judith Butler, há que se "compreender a identidade como uma prática, e uma prática significante, é compreender sujeitos culturalmente inteligíveis como efeitos resultantes de um discurso amarrado por regras, e que se insere nos atos disseminados e corriqueiros da vida lingüística ${ }^{43}$ ". Dessa forma, possível também que se reconheça o nicho populacional de pessoas de SOGI diversa como de necessária proteção específica e cautelosa por parte do direito internacional dos direitos humanos e, especificamente, da Corte Penal Internacional.

Ainda, não se pode esquecer de que essa compreensão das práticas, também, perpassa a noção de que a existência de uma identidade rígida, fixa, é meramente ilusória e perpetuada apenas discursivamente. As regulações se dão dentro de um contexto tempo-espacial, as interpretações dos corpos de modo cultural e, por fim, a partir de um olhar parcial e limitador, que compreende a sexualidade dentro do quadro da heterossexualidade, apenas ${ }^{44}$; uma análise cultural nos permite perceber que desde a medicina até os sistemas de ensino, desde a infância a realidade heterossexual é perpetuada como o padrão e o ideal a ser alcançado e sublinha, mais uma vez, a necessidade de reconhecimento da população LGBTTI como parte de um grupo, dotado de cultura, significação, instituições, vida social, etc., tal como se reconhece em relação a grupos religiosos com suas igrejas, hinos, tradições etc.

De acordo com a jurisprudência já consolidada pelo Tribunal Penal Internacional para Ruanda ${ }^{45}$, considerar

42 LEMKIN, Raphael. American Scholar: The crime of "genocide" defined in internation law. Disponível em: <http://www.preventgenocide.org/genocide/officialtext.htm>. Acesso em: $05 \mathrm{dez}$. 2010 .

43 BUTLER, Judith. Problemas de gênero: feminismo e subversão da identidade. Rio de Janeiro: Civilização Brasileira, 2010. p. 208.

44 BUTLER, Judith. Problemas de gênero: feminismo e subversão da identidade. Rio de Janeiro: Civilização Brasileira, 2010. p. 136.

45 ITERNATIONAL Criminal Tribunal for Rwanda. 
um grupo nos termos do que prevê a norma da Convenção para Prevenção e Repressão do Crime de Genocídio (com texto copiado pelo Estatuto de Roma), deve-se considerar a sua estabilidade como um critério de reconhecimento - excluindo-se, portanto, grupos 'móveis' cuja aderência se daria de forma voluntária, como grupos políticos e econômicos. Ainda, decidiu o Tribunal que, nos casos analisados, a participação no grupo não deveria ser questionada, mas de participação automática e de maneira irremediável. No mesmo sentido, vale dizer que o pertencimento a um grupo deve ser percebido de maneira objetiva e subjetiva ${ }^{46}$, considerando-se as evidencias do caso com base em contextos políticos, sociais e culturais. Tanto devem ser analisadas as particularidades circunstanciais quanto a percepção do autor dos crimes ${ }^{47}$.

Pelo exposto, conclui-se pelo possível reconhecimento de um grupo social formado pelas pessoas de SOGI diversa, pela comunidade LGBTTI, pelos movimentos de orgulho queer etc., o que os qualifica para a proteção internacional à luz do Estatuto de Roma: a uma, pelo teor do artigo $06^{\circ}$ no que concerne ao genocídio; a duas, pela interpretação do Estatuto a partir de uma perspectiva crítica de proteção de gênero, conforme o disposto do Documento Programático exarado pelo Gabinete do Procurador; e, por fim, de acordo com o já consolidado em outras cortes e tribunais internacionais, confirmando a dialogicidade das cortes e suas decisões.

Ainda, assevera-se opinião no sentido de compreender o genocídio para além de uma base biológica, mas

Akayesu, (Trial Chamber), 2 Sept. 1998. p. 511; 516; 701-702. Ver mais nos parágrafos completos, conforme: "The Chamber relied on the travaux preparatoires of the Genocide Convention, which indicate that "the crime of genocide was allegedly perceived as targeting only 'stable' groups, constituted in a permanent fashion and membership of which is determined by birth, with the exclusion of the more 'mobile' groups which one joins through individual voluntary commitment, such as political and economic groups." The Chamber stated that the four groups protected by the convention share a "common criterion," namely, "that membership in such groups would seem to be normally not challengeable by its members, who belong to it automatically, by birth, in a continuous and often irremediable manner." " $\Pi \mathrm{t}$ was necessary . . to respect the intent of the drafters ... which, according to the travaux preparatoires, was clearly to protect any stable and permanent group". Ver tambem: INTERNATIONAL Criminal Tribunal for Rwanda. Musema, (Trial Chamber), 27 Jan. 2000. p. 160-163.

46 International Criminal Tribunal for Rwanda. Rutaganda, (Trial Chamber), 6 Dec. 1999. p. 57-58; 373.

47 International Criminal Tribunal for Rwanda. Semanza, (Trial Chamber), 15 Mayo 2003. p. 317. social, considerando também a possibilidade de positivamente determinarem-se as identidades relativas à comunidade de cidadãos de SOGI diversa, ultrapassando-se leituras reducionistas do texto legal e intentando a proteção de cada cidadão em suas singularidades. Partindo-se de premissas de que as concepções de sexualidade e papeis sociais são temporalidades socialmente construídas ${ }^{48}$, evitam-se divisões puramente binárias para reconhecer todas as potencialidades guardadas pelo indivíduo e o existir dos muitos silêncios que atravessam as estratégias e discursos de dominação e de violação de direitos.

Há que se falar, também, da possibilidade de proteção dos indivíduos de SOGI diversa a partir do artigo $07^{\circ}$ do Estatuto de Roma, no que diz respeito a perseguições. Conforme o texto legal, assim se caracterizam:

\begin{abstract}
Artigo 7o. Crimes contra a Humanidade. 1. Para os efeitos do presente Estatuto, entende-se por "crime contra a humanidade", qualquer um dos atos seguintes, quando cometido no quadro de um ataque, generalizado ou sistemático, contra qualquer população civil, havendo conhecimento desse ataque: [...](h) Perseguição de um grupo ou coletividade que possa ser identificado, por motivos políticos, raciais, nacionais, étnicos, culturais, religiosos ou de gênero, [...], ou em função de outros critérios universalmente reconhecidos como inaceitáveis no direito internacional, relacionados com qualquer ato referido neste parágrafo ou com qualquer crime da competência do Tribunal;
\end{abstract}

Crimes contra a humanidade foram nomeados dessa forma na medida em que vitimizam não somente os indivíduos a quem o crime se orienta, mas igualmente todo e qualquer cidadão do mundo - qualquer pessoa em qualquer país é ofendida por esse tipo de crime simplesmente por possuir a condição humana ${ }^{49}$. Ainda, há que se considerar que os atos de violência, para que caracterizem este tipo de crime, devem empreendidos como parte de um ataque sistemático ou em larga escala, conforme caput do artigo acima citado, e dirigidos à população civilit ${ }^{50}$. Assim, os perpetradores desses crimes se tornam inimigos de toda a população mundial ${ }^{51}$. No mesmo sentido, consolidou entendimento o Tribunal

48 BUTLER, Judith. Problemas de gênero: feminismo e subversão da identidade. Rio de Janeiro: Civilização Brasileira, 2010. p. 141.

49 DRUMBL, Mark A. Atrocity, Punishment, and International Law. New York: Cambridge University Press, 2007. p. 2.

50 BRASIL. Decreto n. 4.388, de 25 de setembro de 2002. Estatuto de Roma do Tribunal Penal Internacional. Disponível em: <http://www. planalto.gov.br/ccivil_03/decreto/2002/D4388.htm>.

51 LUBAN, David. A Theory of Crimes Against Humanity. Georgetown: Law Faculty Publications and Other Works, 2004. p. 90. 
Penal Internacional para a ex-Iugoslávia, senão vejamos:

Whilst rules proscribing war crimes address the criminal conduct of a perpetrator towards an immediate protected object, rules proscribing crimes against humanity address the perpetrator's conduct not only towards the immediate victim but also towards the whole of humankind ... Because of their heinousness and magnitude they constitute egregious attacks on human dignity, on the very notion of humaneness. They consequently affect, or should affect, each and every member of mankind, whatever his or her nationality, ethnic group and location ${ }^{52}$.

També, nesse esteio, é o que consta do Primeiro Relatório da Assembleia Geral das Nações Unidas sobre Crimes Contra a Humanidade. Ademais, sublinha que apesar de não se ignorar a evolução e as alterações temporais que ocorreram em relação a este crime, tendo em vista a Carta de Nuremberg, o Tribunal do Extremo Oriente e as alterações trazidas pela jurisprudência dos Tribunais para Ruanda e Iugoslávia, bem como as divergências doutrinarias que cercam este conceito, trata-se de um crime internacional - o que reitera a possibilidade de ser interpretado de acordo com os tratados relativos de direitos humanos e com o jus cogens. Quanto à sistematicidade, reforça que não é a intenção do legislador tratar crimes isoladamente cometidos com interesses particulares, mas que devem fazer parte de um plano pré-estabelecido. Ainda, que pode ser cometido dentro do território de um único Estado ou para além de suas fronteiras ${ }^{53}$.

Por fim, conforme o texto legal do Estatuto de Roma, o crime tem como elementos a conduta como parte de um ataque generalizado ou sistemático (plano preconcebido) dirigido contra uma população civil e que o autor tenha tido a intenção de que a conduta faça parte de um ataque contra uma população civil. Em direito internacional, um ataque constitui um tipo aberto

52 Em tradução livre: Enquanto as regras prescrevendo crimes de guerra se referem a conduta criminosa de um perpetrador contra um objeto imediatamente protegido, regras prescrevendo crimes contra a humanidade não se referem a condutas praticadas pelo perpetrador contra a vitima em imediato, mas contra toda a humanidade ... devido ao seu caráter abominável e sua magnitude, constituem-se em ataques direcionados à dignidade humana como um todo, à toda a noção de humanidade. Estes crimes constantemente afetam, ou deveriam afetar, todo e cada membro da humanidade, não importando sua nacionalidade, grupo ético e local onde vive. In: International Criminal Court for the former Iugoslavia. Prosecutor v. Erdemović, Appeals Chamber, Judgment, ICTY Case No. IT-96-22-A, p. 21.

53 ORGANIZAÇÃO DAS NAÇÕES UNIDAS. Special Rapporteur on Crimes Against Humanity: International Law Commission. Sixty-seventh session. Geneva, mayo/jun.; jul./aug., 2015. que inclui praticar proibidos pelo ordenamento jurídico e com a participação e intenção do acusado $^{54}$. Não há necessidade do uso de força armada ou de ocorrer durante o contexto de uma guerra, apenas de ser direcionado à população civil ${ }^{55}$ e com grande número de vítimas (natureza coletiva ${ }^{56}$ ), bem como de as práticas serem desumanas e ofensivas aos cidadãos em sua essência ${ }^{57}$.

Tratam-se esses crimes, conforme opinio juris de M. Cheriff Bassiouni, de um crime internacional, também, protegido pelo direito costumeiro, vinculante a todos os Estados e integrante do conjunto de normas peremptórias de direito internacional e do jus cogens ${ }^{58}$. Quanto ao parágrafo específico que trata de perseguição de um grupo como meio de se praticar crimes contra a humanidade, há que se considerar que não foram previsto pelo legislador as razões que motivam a perseguição, os fundamentos daqueles engajados na prática e os meios utilizados $^{59}$. O Estatuto de Roma, apenas, define a severa privação de direitos fundamentais (e não direitos humanos, em uma clara opção metodológica) contrária ao direito internacional; e é por esse motivo que se pretende justificar a possibilidade de identificação de um grupo de pessoas de SOGI diversa como possível alvo a quem se direcionam estes crimes - e, portanto, perseguição destas pessoas enquanto crime contra a hu-

54 Estatuto de Roma da Corte Penal Internacional, Art.7(2)(a); Tribunal Penal Internacional para a Ex Iugoslávia. Prosecutor vs. Tadic, par.644; Tribunal Penal Internacional para Ruanda, Prosecutorvs.Akayesu, p. 205.

55 BOAS, Bischoff. Elements of Crimes Under International Law: the attack requirement. Cambridge: Cambridge University Press, 2008. p.41.

56 Tribunal Penal Internacional para a Ex Iugoslávia. Prosecutor vs. Tadic,par.644; Tribunal Penal Internacional para Ruanda, Prosecutorvs.Akayesu, p. 233, par.644.

57 Tribunal Penal Internacional para Ruanda. Prosecutor vs. Laurent Semanza. 97-20. Julgamento e Sentença, p. 327.

58 Conforme a Convenção de Viena sobre o Direito dos Tratados, de 23 de Maio de 1969, artigo 53."Tratado em Conflito com uma Norma Imperativa de Direito Internacional Geral (jus cogens): É nulo um tratado que, no momento de sua conclusão, conflite com uma norma imperativa de Direito Internacional geral. Para os fins da presente Convenção, uma norma imperativa de Direito Internacional geral é uma norma aceita e reconhecida pela comunidade internacional dos Estados como um todo, como norma da qual nenhuma derrogação é permitida e que só pode ser modificada por norma ulterior de Direito Internacional geral da mesma natureza". (grifos nossos).

59 BASSIOUNI, M. Cherif. Expert Opinion on Scott Lively vs. SMUG. Civil Action 3:12 - CV - 30051, nov. 2015. Disponível em:< https://docs.google.com/viewerng/viewer?url=http:// files.eq cf.org/wp-content/uploads/2016/05/ Bassiouni-Expert-OpinionSexual-Minorities-Uganda-v-Lively..pdf> . Acesso em: 14 dez. 2016. 
manidade. Nas palavras do mesmo autor, em documento relativo ao caso Scott Lively vs. Sexual Minorities in Uganda, assim percebemos:

\begin{abstract}
Primeiramente, (aqueles que não se enquadram estritamente em categorias heterossexuais ou de conformidade de gênero) é um grupo distinguível dentro de uma população civil; em segundo lugar, isolar ou retirar direitos sociais e proteção destes grupos, subjugando-os a processos criminais e prisão baseado em seu status ou identidade constitui violação de natureza física e psicológica. Ainda, quando esta conduta está prevista em lei, reveste-se de caráter sistemático e de larga escala ${ }^{60}$.
\end{abstract}

Pelos motivos acima elencados, considerando o constante no Estatuto de Roma no que se refere a perseguição, bem como a possível identificação de pessoas de SOGI diversa como integrantes de um grupo, objetiva e subjetivamente, há que se sustentar sua proteção em termos de direito internacional e conforme o Estatuto de Roma, em seu texto legal e a partir da interpretação referida pelo Gabinete do Procurador no Documento Programático acima referenciado. Portanto, justificadas estão as possibilidades de pessoas de orientação sexual e identidade de gênero diversas serem contempladas pela proteção da Corte Penal Internacional não obstante $o$ expressamente contido em seu código normativo.

Ora, as incursões conceituais pretendidas neste trabalho, portanto, pretendem que se possibilite dar início a uma nova realidade de litigância em busca de proteção e reconhecimento judicial às identidades de pessoas que não se enquadram na matriz heterossexual vigente. Os exercícios do poder, ao atravessar as relações e tomar por objeto os cidadãos em sua multiplicidade, alteram as percepções que se têm tanto de um nicho populacional de quem os compreende tanto da ideia que possuem de si mesmos, como comunidade e como indivíduo. $\mathrm{E}$ essa redução dos indivíduos e das comunidades por eles formadas, a objetos de Realpolitiks e a vítimas de crimes internacionais (como genocídio e crimes contra a humanidade) colocam em risco todos os tratados de direito internacional assinados no último século, bem como a dignidade e vida social de cada vivente do mundo.

60 BASSIOUNI, M. Cherif. Expert Opinion on Scott Lively vs. SMUG. Civil Action 3:12 - CV - 30051, nov. 2015. Disponível em:< https://docs.google.com/viewerng/viewer?url=http:/ / files.eq cf.org/wp-content/uploads/2016/05/ Bassiouni-Expert-OpinionSexual-Minorities-Uganda-v-Lively..pdf>. Acesso em: 14 dez. 2016.

\section{Considerações Finais}

Consideradas as adversidades existentes na elaboração, assinatura e ratificação de tratados internacionais, mormente, quando tratam de direitos humanos e de uma tentativa de harmonizar diversas culturas e interesses, perspectivas universais e particulares de direitos, percebemos que as práticas podem ganhar contornos ainda maiores de dificuldade quando se referem a questões envolvendo gênero e sexualidade.

Intensificam-se, ainda, os efeitos da Realpolitiks quando, por exemplo, o Estatuto de Roma da Corte Penal Internacional quando se propõe a acomodar interesses e premissas de mais de 60 países - europeus, orientais, liberais, conservadores etc. $\mathrm{Na}$ ânsia de consolidar o antigo projeto de criação de uma corte permanente e complementar às jurisdições domésticas que tantas vezes se mostraram insuficientes em processar e julgar graves violações de direitos humanos, algumas alterações na proposta original do Estatuto de Roma foram efetuadas para rearranjar os interesses de países tão diversos. Dessa forma, integrou-se ao ER a controversa ressalva de que “o termo 'gênero' abrange os sexos masculino e feminino, dentro do contexto da sociedade, não lhe devendo ser atribuído qualquer outro significado".

Para além de considerações éticas da elaboração desse trecho ou do abandono dos interesses originais da justiça internacional, de comprometimento com os direitos humanos e os cidadãos, tendo em vista os interesses particulares que levaram à positivação destas considerações em detrimento do que seria esperado para que se atingissem os objetivos iniciais de uma corte ou da proteção dos direito humanos, há que se refletir sobre as possíveis formas de elastecer a proteção dos cidadãos e prover maior justiça material a eles - principalmente quando consideramos a vulnerabilidade do grupo de pessoas em não conformidade com a heterossexualidade hegemonicamente dominante.

Oficialmente, um primeiro passo foi dado com o Documento Programático do Gabinete do Procurador para Crimes Sexuais e de Gênero, em um compromisso de análise crítica e direcionada de todos os crimes previstos no Estatuto de Roma a partir de uma perspectiva de gênero e sexualidade. Nesse sentido, compreender as diferenças e desigualdades existentes entre homens e mulheres, entre heterossexuais e todos aqueles que de outra forma se identificam, os exercícios de poder 
que perpassam as relações sociais e as construções de gênero e sexualidade que podem influenciar nas graves violações que preocupam ao direito internacional.

Portanto, é a partir dessa perspectiva que se propuseram duas possibilidades de pensar no Estatuto de Roma como um instrumento de proteção das populações de SOGI diversa. A partir do reconhecimento dessas pessoas como portadores de uma identidade a ser protegida e valorizada, possibilitando a vida e o exercício das singularidades de todos os cidadãos e evitando-se tentativas de homogeneização social, a intenção é que sejam reconhecidos como um grupo social. Ora, uma vez que a existência política de grupos populacionais se relaciona com controle, proteção, presunções e construções sociais - constituídos de forma política e jurídica, não biológica, não há motivo para que aqueles que não possuem a vida regida por uma matriz de heterossexualidade deixem de ser considerados como objeto de invisibilidades e vulnerabilidades e, portanto, merecedores de um olhar mais atento do direito internacional dos direitos humanos.

Pelo exposto, as diversas atitudes empreendidas no sentido de extinguir a população de SOGI diversa, de subjugá-la e inferiorizá-la, devem ser evitadas e punidas na medida em que reiteradamente causam ofensas graves à integridade física e mental dos cidadãos. Ainda, as diversas violações que instrumentalizam a tentativa de destruição desta população devem ser percebidas com especial atenção no sentido de que atos de genocídio não voltem a se repetir, que o horror das guerras do último século não ecoem ainda mais fortemente no presente, de que a paz e a justiça caminhem juntas à luz do direito internacional dos direitos humanos.

Da mesma forma, sendo o genocídio uma forma agravada dos crimes contra a humanidade, que violam a integridade, a segurança e a dignidade de todos os cidadãos do mundo, existindo ataques a este grupo populacional, em termos de direito internacional, e sendo ele generalizado ou sistemático, há que se subsumir os fatos à inteligência do artigo $07^{\circ}$ do ER, no que concerne à perseguição. Sem que se olvide dos tratados de direito internacional que protegem os direitos humanos, das normas de direito cogente e do compromisso da Declaração Universal dos Direitos Humanos, ações e omissões estatais que isolem ou retirem direitos, afrontem identidades e causem violações de natureza física ou psicológica àqueles que não se enquadram estrita- mente em categorias heterossexuais ou de conformidade de gênero devem ser processadas e julgadas - se não em âmbito doméstico, sob a jurisdição da Corte Penal Internacional, como perfeitamente possível pela leitura do ER a partir de uma perspectiva crítica de gênero e do diálogo com as demais cortes e decisões internacionais que intentam a proteção dos direitos humanos.

Sugeridas novas formas de interpretação do Estatuto de Roma e duas possibilidades de proteção da população de SOGI diversa com base no referido dispositivo de normas, uma nova esperança se delineia no futuro do direito internacional dos direitos humanos. Confiar na proposta do Documento Programático analisado, bem como na efetivação das intenções da Corte Internacional Penal para além da política e dos interesses particulares, lança novos contornos para as pessoas vulnerabilizadas e inviabilizadas em razão de suas sexualidades.

Reitera-se que a proposta compreensão de pessoas de orientação sexual e identidade de gênero diversas como uma minoria civil em busca de direitos sociais não ocorre sem críticas, de forma linear ou natural. O que se sublinha, todavia, é a artificialidade de alocação deste grupo, desta forma, com base em explicações biológicas ou religiosas, mas sim na fluidez de como a percepção social se opera por intermédio das relações. Assim, o que se pretendeu demonstrar é que resta imprescindível a compreensão de pessoas em não conformidade heterossexual como um grupo social que necessita de especial atenção do Direito e das cortes internacionais, especialmente a CPI, para que graves violações deixem de se repetir - bem como ultrapassar as limitações do Direito como mera aplicação de normas e, ao fim, possibilitar sua existência como garantidor da multiplicidade e das diversas nuances do gênero e da sexualidade humana.

\section{REFERÊNCIAS}

ARENDT, Hannah. As Origens do Totalitarismo. São Paulo: Companhia das Letras, 1990.

ARENDT, Hannah. Eichmann em Jerusalém: um relato sobre a banalidade do mal. Tradução: José Rubens Siqueira. 5. reimpr. São Paulo: Companhia das Letras, 1999.

ARON, Raymond. Paz e Guerra entre as Naçoes. Brasília: Universidade de Brasília, Instituto de Pesquisa de Re- 
lações Internacionais; São Paulo: Imprensa Oficial do Estado de São Paulo, 2002.

BASSIOUNI, M. Cherif. Expert Opinion on Scott Lively vs. SMUG. Civil Action 3:12 - CV - 30051, nov. 2015. Disponível em: <https://docs.google.com/viewerng/ viewer?url=http://files.eq cf.org/wp-content/uploads/2016/05/ Bassiouni-Expert-Opinion-SexualMinorities-Uganda-v-Lively..pdf $>$. Acesso em: 14 dez. 2016.

BASSIOUNI, M. Cherif. Searching for Justice in the World of Realpolitik: 12 Pace Int'l L, 2000. Disponível em: <http://digitalcommons.pace.edu/pilr/vol12/ iss2/1>. Acesso em: 18 nov. 2016.

BOAS, Bischoff. Elements of Crimes Under International Law: the attack requirement. Cambridge: Cambridge University Press, 2008.

BRINGING Justice: the Special Court for Sierra Leone. Reported at Human Rights Watch em tradução livre. Disponível em: <http://www.hrw.org/node/11983 / section/2>. Acesso em: 24 out. 2014.

BUTLER, Judith. Problemas de gênero: feminismo e subversão da identidade. Rio de Janeiro: Civilização Brasileira, 2010.

CLARK, James M. Forced Marriage: The Evolution of a New International Criminal Norm. University of Aberdeen, 2013. v. 3.

Corte Especial para Serra Leoa. Promotor vs. Alex Tamba Brima. Caso n. SCSL-2004-16-A. Julgamento de 3 mar. 2008.

DELMAS-MARTY, Mireille; CASSESSE, Antonio. Crimes Internacionais e Jurisdições Internacionais. Barueri: Manole, 2004.

DRUMBL, Mark A. Atrocity, Punishment, and International Law. New York: Cambridge University Press, 2007.

ENCICLOPAEDIA Brittanica. Disponível em: $<$ https://global. britannica. com/topic/realpolitik>. Acesso em: 10 nov. 2016.

ESKRIDGE JUNIOR, William N. January 27, 1961: The Birth of Gay legal Equality Arguments. Local: Faculty Scholarship Series. 2001.

ESKRIDGE JUNIOR, William N. Some Effects of Identity-Based Social Movements on Constitutional Law in the Twentieth Century. Local: FacultyScholarship Series, 2002. p. 3767.
FERREIRA, Gustavo Bussmann. A Identificação das Vitimas para o Direito Internacional dos DireitosHumanos: entre a universalidade dos direitos e a vida nua. Disponível em: <http://acervodigital.ufpr.br/bitstream/handle/1884/37933/R\%20-\%20D\%20-\%20 GUSTAVO \%20BUSSM ANN\%20FERREIRA. pdf? sequence $=3>$. Acesso em: 17 nov. 2016.

International Criminal Tribunal for Rwanda. Musema, (Trial Chamber), January 27, 2000.

International Criminal Tribunal for Rwanda. Rutaganda, (Trial Chamber), December 6, 1999.

International Criminal Tribunal for Rwanda. Semanza, (Trial Chamber), May 15, 2003.

Iternational Criminal Tribunal for Rwanda. Akayesu, (Trial Chamber), September 2, 1998.

KELLY, Duncan. Realpolitik: a history, by John Bew. Financial Times, 2016. Disponível em: <https:// www.ft.com/content/802c822e-d0d6-11e5-831d09f7778e7377>. Acesso em: 17 nov. 2016.

KENNEDY, David M. Center for International Studie: What's the Argument for "Gender Justice?”. Disponível em: <http://www.legal-tools.org/uploads/tx_ltpdb/ Oosterveld _Gender_HarvardArticle2005_02.pdf $>$. Acesso em: 20 nov. 2016.

KIM, Hunjoon; SIKKINK Kathryn. Explaining the Deterrence Effect of Human Rights Prosecutions for Transitional Countries. 2009. Disponível em: <http://iilj. org/courses/documents/Sikkink-Kim.HC2009Oct21. pdf $>$. Acesso em: 5 set. 2016.

KONNOTH, Craig J. Created in Its Image: The Race Analogy, Gay Identity, and Gay Litigation in the 1950s1970s. The Yale Law Journal, v. 119, n. 2, Nov. 2009.

LAFER, Celso. A Reconstrução dos Direitos Humanos: a contribuição de Hannah Arendt. Estud.av, São Paulo, v. 11, n. 30, mayo/aug. 1997. Disponível em: <http:// dx.doi.org/10.1590/ S0103-40141997000200005>. Acesso em: 20 jun. 2014.

LAFER, Celso. Reconstrução dos direitos bumanos: um diálogo com o pensamento de Hannah Arendt. Rio de Janeiro: Companhia das Letras, 2001.

LEMKIN, Raphael. American Scholar. The crime of "genocide" defined in internation law. Disponível em: <http://www.preventgenocide.org/ genocide/ officialtext.htm>. Acesso em: 5 dez. 2010. 
LUBAN, David. A Theory of Crimes Against Humanity. Georgetown: Law Faculty Publications and Other Works, 2004.

MORGENTHAU, H. A politica entre as Nações. Brasília: Funag/IPRI, EdUNB; São Paulo: Imprensa Oficial do Estado, 2003.

OOSTERVELD, Valerie. Diplomatic Conference of Plenipotentiaries on the Establishment of the International Criminal Court, Notes From Working Group on Applicable Law. 1998. p. 63. Disponível em: <http://www.legal-tools.org/ uploads/tx_ltpdb/Oosterveld _Gender_HarvardArticle2005_02.pdf>. Acesso em: 20 nov. 2016.

OOSTERVELD, Valerie. The Defintion of "Gender" in the Rome Statute of the International Criminal Court. a Step Forward or Back for International Criminal Justice? Disponível em: <http://www.legal-tools.org/uploads/tx_ 1tpdb/Oosterveld _Gender_HarvardArticle2005_02. pdf>. Acesso em: 20 nov. 2016.

ORGANIZAÇÃO DAS NAÇÕES UNIDAS. Role of Civil Society in Post-Conflict Peace-Building: 4993 encontro do Conselho de Segurança, 22 jun. 2004. Nova Iorque. Disponível em: <http://www. securitycouncilreport. org/ atf/cf/\%7B65BFCF9B-6D27-4E9C-8CD3CF6E4FF96FF9\%7D/PKO\%20SPV \%204993.pdf>. Acesso em: 10 out. 2014.
ORGANIZAÇÃO DAS NAÇÕES UNIDAS. Special Rapporteur on Crimes Against Humanity: International Law Commission. Sixty-seventh session. Geneva, mayo/ jun.; jul./aug., 2015.

PREFEITURA DE NOVA YORK. Orientações legaispara identidades e expressão de gênero. Disponível em: < https:/ / www1.nyc.gov/site/cchr/law/legal-guidances-genderidentity-expression.page\#2>. Acesso em: 20 nov. 2016.

RICHARDS, David J. Identity and the Case for Gay Rights. Chicago: University of Chicago Press, 1999.

SCHABAS, William A. An Introduction to the International Criminal Court. 4. ed. New York: Cambridge University Press, 2011.

SCHARF, Michael P. Forward: Lessons from the Saddam Trial. Local: Faculty Publications; Case Western Reserve University, 2007.

Tribunal Penal Internacional para a Ex-Iugoslávia. Estatuto do Tribunal Penal Internacional para a ExIugoslávia, de 25 de maio de 1993.

Tribunal Penal Internacional para a Ex-Iugoslávia. Promotor vs. Kunarac (12 Prosecutor vs. Kunarac et al.). Caso n. IT-96-23T \& IT-96-23/1-T, Julgamento de 22 fev. 2001. 
Para publicar na Revista de Direito Internacional, acesse o endereço eletrônico www.rdi.uniceub.br ou www.brazilianjournal.org.

Observe as normas de publicação, para facilitar e agilizar o trabalho de edição. 